\title{
Leonardo da Vinci's studies of friction
}

Ian M. Hutchings

University of Cambridge, Department of Engineering, Institute for Manufacturing, 17 Charles Babbage Road, Cambridge CB3 OFS, UK

email:imh2@cam.ac.uk

\begin{abstract}
Based on a detailed study of Leonardo da Vinci's notebooks, this review examines the development of his understanding of the laws of friction and their application. His work on friction originated in studies of the rotational resistance of axles and the mechanics of screw threads. He pursued the topic for more than 20 years, incorporating his empirical knowledge of friction into models for several mechanical systems. Diagrams which have been assumed to represent his experimental apparatus are misleading, but his work was undoubtedly based on experimental measurements and probably largely involved lubricated contacts. Although his work had no influence on the development of the subject over the succeeding centuries, Leonardo da Vinci holds a unique position as a pioneer in tribology.
\end{abstract}

Keywords: sliding friction; rolling friction; history of tribology; Leonardo da Vinci 


\section{Introduction}

Although the word 'tribology' was first coined almost 450 years after the death of Leonardo da Vinci (1452 - 1519), it is clear that Leonardo was fully familiar with the basic tribological concepts of friction, lubrication and wear. He has been widely credited with the first quantitative investigations of friction, and with the definition of the two fundamental 'laws' of friction some two hundred years before they were enunciated (in 1699) by Guillaume Amontons, with whose name they are now usually associated. These simple statements, which have wide applicability, are:

- the force of friction acting between two sliding surfaces is proportional to the load pressing the surfaces together (i.e. the forces have a constant ratio, often called the coefficient of friction), and

- the force of friction is independent of the apparent area of contact between the two surfaces.

Certain drawings from Leonardo's notebooks have become iconic among tribologists, and have been reproduced widely. These sketches were first brought to the general attention of the community by Dowson [1] in his monumental study of the history of tribology. They show (Fig.1a) blocks being dragged along planes with various inclinations, and (Fig.1b) a set of similar blocks in different orientations on a horizontal plane, as well as (Fig.1c) a block resting on a horizontal surface and attached to a string that passes over a cylinder and supports a hanging weight, and a horizontal cylinder lying in a hemicylindrical cavity with a string attached to a hanging weight. However, most researchers in tribology are unaware of the great richness of Leonardo's work in their subject, or of the wider context in which he carried it out. This article aims to explore in detail what Leonardo understood about friction, based on 
a wide-ranging chronological study of his surviving notebooks. His work on wear will form the basis of a subsequent article.

(a)

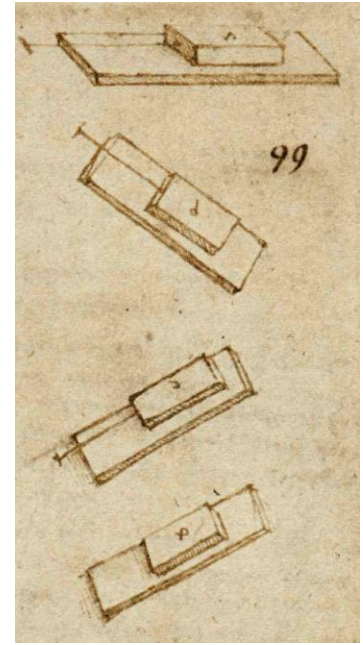

(b)

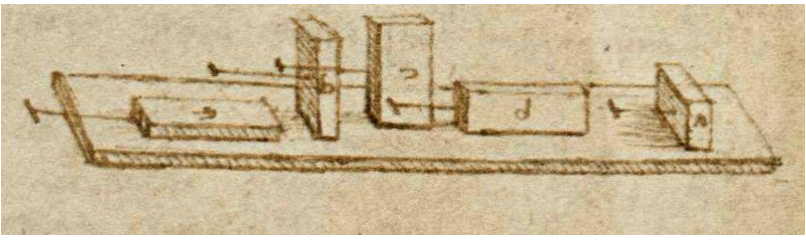

(c)

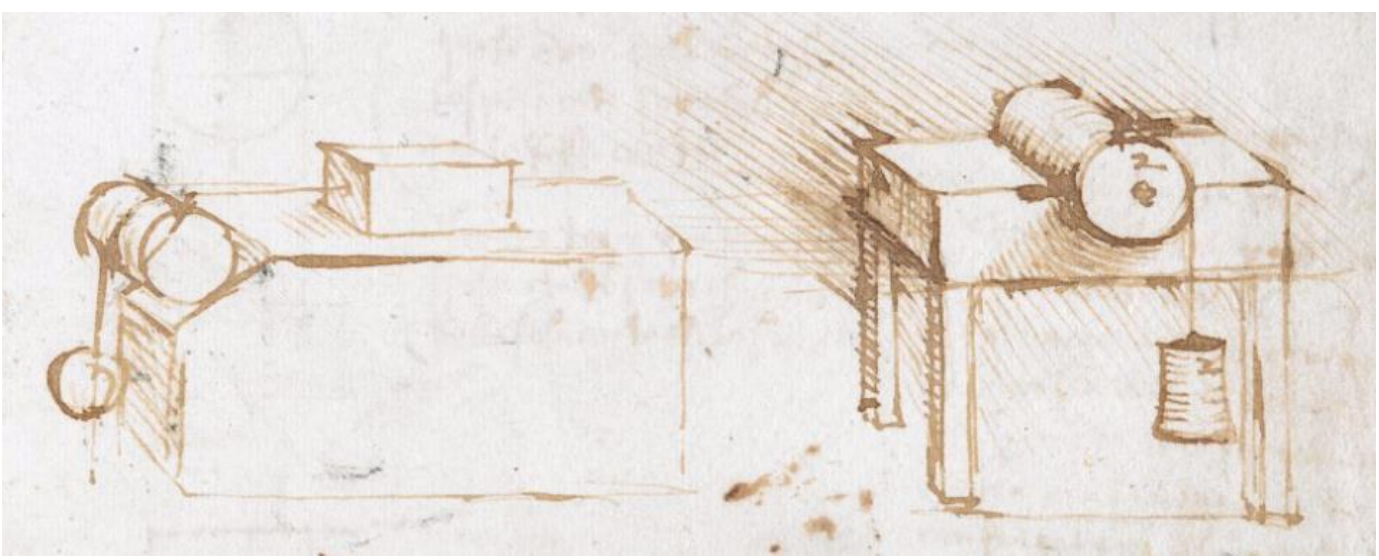

Fig. 1 Sketches from two different pages in Leonardo's notebooks: (a, b) from Codex Atlanticus, Biblioteca Ambrosiana, Milan (CA folio 532r c. 1506-8), and (c) from Codex Arundel, British Library, London (Arundel folio 41r c. 1500-05)

\section{The notebooks}

Leonardo's notebooks comprise a diverse collection of writings and sketches with a complex history. The notes in them are almost all written in his distinctive 'mirror' writing, 
from right to left ${ }^{1}$. He also employed numerous abbreviations and contractions, with no punctuation, and wrote in his native Florentine at a time when Italian spelling and grammar forms were far from standardized. ${ }^{2}$

It has been suggested that the more than 6000 pages now known to us may perhaps represent only half, or even a quarter or less of his total output, the rest having been lost $[2,3$, 4]. Over time, many of these separate sheets have been rearranged, rebound and even in some cases dissected into smaller pieces [5]. The various collections (called codices or manuscripts) in their present states are in some cases quite heterogeneous in both subject matter and date. For example, the sheets which make up both the Codex Atlanticus and the Codex Arundel were produced over a period of some 40 years from 1478 to 1518 . Some other collections are more uniform in date and topic. Leonardo worked energetically, often on several different subjects and in more than one notebook concurrently, and took little care to arrange his writings thematically or to record dates or places. In some cases, he wrote rough notes in one place, and then used them as the basis for a more polished version elsewhere, either at roughly the same time or much later. For example, much of the material in Codex Madrid I is derived from notes found in the Codex Atlanticus and Paris Manuscripts H, I and M [6]. Some of his drawings are more highly polished than others, allowing one to trace a progressive development from a working sketch to an elegant illustration suitable for a published treatise; but while Leonardo apparently intended eventually to publish much of his work, that never happened. The contents of his notebooks remained largely unknown until the late $19^{\text {th }}$ century (1883) when Jean Paul

\footnotetext{
${ }^{1}$ Nearly all his notes are written in this manner, but the numbers and letters on diagrams sometimes read conventionally, from left to right. In some cases both methods occur on the same sketch.

2 For example the noun he used for 'friction' was 'confregazione', derived from the verb 'confregare' meaning 'to rub together', and not the modern Italian term 'attrito'. In most instances 'confregazione' can be translated as 'friction', but in some cases Leonardo was clearly referring to the act of rubbing which then led to wear.
} 
Richter published transcriptions and English translations of substantial amounts of text with some accompanying sketches [7], although a few extracts had been published before then.

The notebooks themselves, which can now be consulted in facsimile form and also online with transcriptions ${ }^{3}$, present an apparently chaotic and potentially confusing mass of written and diagrammatic material in rough and incomplete note form. On several topics Leonardo repeats himself. As we shall see below, in statements about friction he does this many times. At the beginning of one notebook (the Codex Arundel) he even writes explicitly 'I fear that before I have completed this I shall have repeated the same thing several times, for which do not blame me, reader, because the subjects are many, and the memory cannot retain them and say, this I will not write because I have already written it. And to avoid this it would be necessary, with every passage I wanted to copy, to read through everything I had already done so as not to replicate it.' (Arundel 1r, 1508). Any student of his writings quickly becomes aware that Leonardo seldom pauses to reflect on what he has already written: his thoughts are moving far too rapidly, both linearly and tangentially, for that.

The original notebooks are now widely dispersed, although nearly all are in Europe. The collections which contain material relating to tribology are the Codex Atlanticus in the Biblioteca Ambrosiana in Milan (cited here as CA), the two Madrid Codices in the Biblioteca Nacional which became lost and were only rediscovered in the mid-1960s (Madrid I and II), the Paris Manuscripts in the Bibliothèque de l'Institut de France (notably MSS A, E, F, G, H, I, L and M), and two collections in London: the Codex Arundel (Arundel) in the British Library and two of the three Forster Codices (Forster II and III) in the Victoria and Albert Museum. There are also a few relevant sheets in the Royal Collection at Windsor Castle

\footnotetext{
${ }^{3}$ Biblioteca Leonardiana: e-Leo, Archivio digitale di storia della tecnica e della scienza, www.leonardodigitale.com
} 
(Windsor). Pages are conventionally referred to by the number of the folio (leaf) followed by the letter 'r' (recto) or 'v' (verso) 4 .

In exploring and evaluating Leonardo's work on tribological topics, one would ideally like to know the dates at which the relevant notes or sketches were produced. This is now possible with reasonable accuracy thanks to the painstaking studies of various scholars, notably Carlo Pedretti who has published chronologies for pages in the Codex Atlanticus [8] and the Codex Arundel [9], and the relevant fragments at Windsor [10]. Dates for the Forster Codices have been taken from Marinoni [11] and for the Madrid Codices from Reti [12], while dates for the other notebooks have been taken from the list provided by Pedretti [6].

\section{Previous descriptions of Leonardo's work on friction}

The first, very brief, acknowledgement of Leonardo's work on friction was provided in 1797 by Giovanni Battista Venturi, the Italian physicist noted for his contributions to hydraulics [13]. Venturi published a commentary and some brief extracts from a collection of Leonardo's notebooks that had been moved to Paris from the Ambrosian Library in Milan in 1796 following Napoleon's conquest of northern Italy [5]. The notebooks now known as the Paris Manuscripts form part of that collection, while the material returned to Milan after 1815 now forms the Codex Atlanticus. Venturi included French translations of some of Leonardo's notes on physics, astronomy and geology, and made the terse statement that, among other matters in mechanics, Leonardo 'knew the laws of friction later stated by Amontons'. He had intended to publish a more complete account of Leonardo's notebooks but never did so. In 1840 Guglielmo Libri, professor of mathematics but now better known for his wholesale theft of books and manuscripts including some of Leonardo's, provided only a marginally fuller

\footnotetext{
${ }^{4}$ The Codex Atlanticus was reassembled and repaginated in the late 1960s; the current folio references are used here.
} 
description [14] based on studies of the Paris manuscripts and also the Codex Atlanticus. Libri wrote that 'Leonardo was passionate about mechanics, which he called the paradise of the sciences, and he studied it theoretically and practically.....It was he who introduced consideration of friction to mechanics; he calculated its effect from a series of experiments.'

More detail, including the first direct quotations of some of Leonardo's statements on friction, all taken from a single folio of the Codex Atlanticus (CA 558r), was subsequently provided in 1872 by the Italian physicist and historian of science Gilberto Govi [15]. Two years later the first description of Leonardo's work on friction appeared in English, when Charles Christopher Black of the South Kensington Museum, London (later to become the Victoria and Albert Museum), commented in hagiographic terms and at some length on a small part of the scientific work contained in the Codex Atlanticus [16]. He included quotations from Leonardo's notes, translated in a flowery and in places unclear style. One might wonder how it was that Black, a museum curator whose other publications were all in the fine arts, could write with such confident authority about Leonardo's work on friction, even though some parts of what he wrote are confusing and even nonsensical. The answer is that nearly all of Black's account, and indeed much of the rest of his long essay on Leonardo's scientific work, was translated and copied word for word, but with an imperfect understanding of its meaning, from Govi's original publication of two years earlier, and presented with scant acknowledgement of its source. Gabriel Séailles, professor of philosophy at the Sorbonne, published an extensive treatise in French on Leonardo's artistic and scientific work in 1892 and also reproduced part of Govi's account of his work on friction, but in his case gave full credit to the original author [17]. Other nineteenth century authors such as Grothe [18] in a treatise on Leonardo's engineering and philosophical work, and Beck [19], writing on the history of mechanical engineering, also clearly drew heavily and exclusively on Govi's essay for their brief comments on Leonardo's studies of friction. 
Richter's translations of material from the notebooks [7] contained very little on technical subjects; indeed, he deliberately excluded science and technology and made no reference to tribological topics. Although Richter's work was later extended in a second edition by his daughter [20], no scientific material was added. It was MacCurdy in a comprehensive collection of translated extracts published in 1938 [21] who provided the first widely accessible publication in English of some of Leonardo's notes on friction and wear. However this translator was not familiar with tribological concepts or technical terminology, and some of the extracts are therefore unnecessarily obscure. Even more importantly, MacCurdy did not reproduce the sketches which are in many cases essential to understanding Leonardo's words, and in some cases appear in the notebooks with only the briefest associated note or even unaccompanied by any relevant text at all.

A succession of researchers in the twentieth century analysed Leonardo's studies of mechanics, of which his work on friction formed part. Pierre Duhem examined Leonardo's understanding of statics [22] and his other studies of mechanics in great detail in the context of his scientific antecedents and successors [23], but made no reference to his studies of friction. Nor did Schuster [24] in a critical review of Leonardo's studies of balances, the mechanics of pulleys and the load-carrying capacity of columns and beams. Hart [25] provided some brief comments on Leonardo's work on friction which appear to be based on those of Séailles [17].

In 1933 Marcolongo presented extracts from Leonardo's statements on friction in Codex Atlanticus and Codex Arundel and reproduced the sketches shown in Fig. 1(c), but while stressing that Leonardo's work predated that of Amontons and Coulomb, he did not attempt a critical discussion [26]. In 1939, in association with a major exhibition in Milan to celebrate Leonardo's work both Marcolongo [27] and Canestrini [28] contributed essays that included comments on his studies of friction, and the latter reproduced several relevant 
sketches from the Codex Atlanticus and Codex Arundel. Canestrini also produced a more detailed review based on these two sources as well as the Forster notebooks and the Paris manuscripts, and reproduced all the sketches of Fig. 1 [29]. He specifically noted, however, that he was unable to establish a chronology of Leonardo's work on friction. In 1940 Uccelli [30] published a comprehensive compilation of Leonardo's notes and diagrams on mechanics drawn from all the notebooks then known, arranged thematically to simulate the kind of 'treatise' that Leonardo himself had expressed an intention to produce; Uccelli's book contains extensive coverage of friction and remains a valuable resource to complement the original notebooks.

Leonardo's contributions were first brought explicitly to the attention of the 'tribological' community (as it then existed) in 1950 with the publication of Bowden and Tabor's first book on friction and lubrication [31]. From a quotation in the frontispiece to the first paragraph of the introduction and several chapter and section headings, Leonardo's statements (from MacCurdy's translations) form a thread that runs through the whole book. Two quotations from Leonardo's notebooks are particularly noteworthy: 'friction produces double the amount of effort if the weight be doubled', and 'friction made by the same weight will be of equal resistance at the beginning of the movement though the contact may be of different breadths or lengths'. In their second book [32] the same authors provided a brief historical survey of early work on friction, and included the same two quotations from Leonardo, but also added that for smooth polished surfaces sliding together 'every frictional body has a resistance of friction equal to one quarter of its weight'. Neither book included any of Leonardo's sketches, although in a later short introductory text on friction published in 1974 [33] they did reproduce the sketches shown in Fig. 1(a) and (b), with a brief summary of Leonardo's contributions. 
With the rediscovery of the Madrid Codices in 1967, Leonardo's studies of mechanics, including his work on friction, wear and the design of bearings, received new attention, initially by Reti [34]. Dowson's book [1] (which followed an earlier short article [35]) provided the first comprehensive discussion by a tribologist of Leonardo's remarkable contributions to the study of friction and has been widely cited. Both Dowson and Reti also reviewed Leonardo's studies of wear and bearing design, which are outside the scope of this article.

\section{The laws of friction}

By using the sources of chronological information cited in section 2, we can establish that Leonardo's surviving notes on friction were written over a period of some twenty years between 1493-4 and about 1515. His earliest surviving statement which relates to the laws of friction is particularly interesting and merits close scrutiny ${ }^{5}$. It is contained on a tiny page (only 92 by $63 \mathrm{~mm}$ ) of one of the Forster Codices (Forster III 72r) and is reproduced in Fig. 2. This folio has received attention from art historians because at the top of the page, in black pencil, Leonardo has sketched the head of an old woman accompanied by the words ' $\cos a$ bella mortal passa e non dura', which can be translated as 'mortal beauty passes and does not endure.' The Italian is a direct quotation from one of Petrarch's sonnets. However, Leonardo's handwriting had previously been incorrectly transcribed by Richter [7] who translated it as 'what is fair in men passes away, but not in art', a statement which is still sometimes falsely attributed to Leonardo. McCurdy [36] related the sketch of the head to comments made elsewhere by Leonardo, quoting Ovid, on the ageing of Helen of Troy, and

\footnotetext{
${ }^{5}$ There are slightly earlier comments in MS A (9r and 30v, c. 1490-2) about the effect of area of contact on friction. Leonardo observes that a length of rope extended over the ground needs a greater force to drag it than the same piece of rope coiled into a ball. Forster III also contains some other, qualitative notes on friction in the context of the abutments of an arch (folios $4 v$ and $79 v$ ), the torque on a millstone (46v), and the force exerted by a chimney-sweep on the walls of a chimney to prevent himself sliding downwards $(19 \mathrm{v})$.
} 
Keele [5] has even suggested that the sketch is intended to represent the aged Helen. In correcting Richter's mistake in transcription, Maclagan [37] noted that the rest of the page 'is occupied with irrelevant notes and diagrams in red chalk'. However, it is these 'irrelevant' marks that are of primary interest to the tribologist.

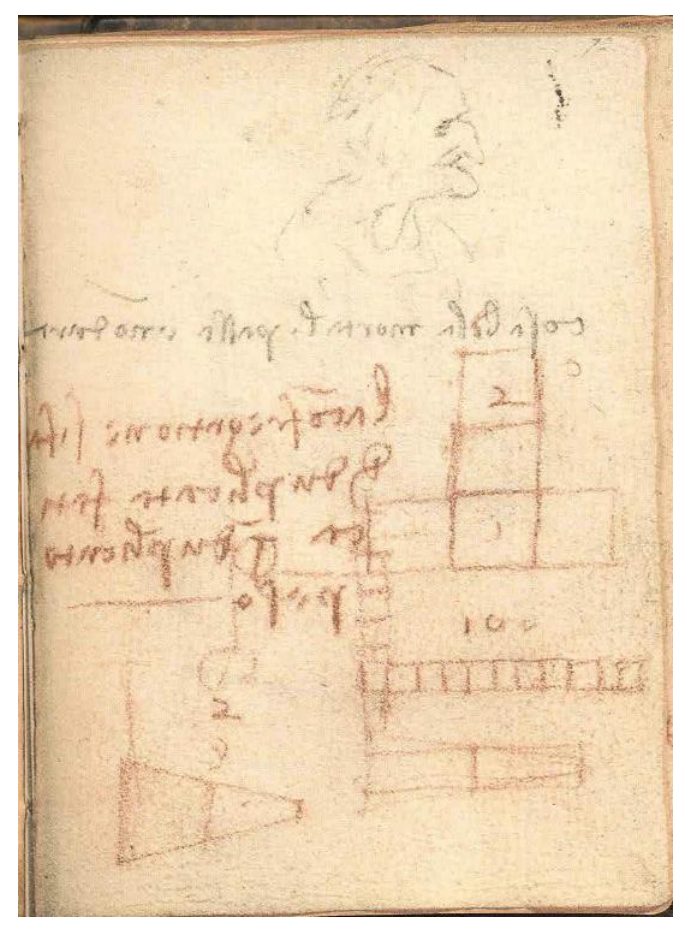

Fig. 2 Leonardo's first note and sketches relating to the laws of friction, probably written in 1493 and certainly before September 1494 (Forster III 72r, Victoria and Albert Museum, London).

The page, from a notebook written between 1493 and September 1494 [11], is typical of Leonardo, with his frugal use and re-use of paper and his employment of both writing and sketches to record his thoughts. Beneath the drawing of the woman's head and the quotation, and very probably predating them because the black pencil overlaps the red marking, we find another quick sketch, drawn roughly with the red chalk used on most of the other pages of this notebook $^{6}$. This shows three square blocks being pulled to the left by a string which passes

\footnotetext{
${ }^{6}$ Additional evidence that the drawing of the head is a later addition comes from the use of black pencil which is very rare in this notebook; folio $72 \mathrm{r}$ is the only page in the whole book of 88 folios on which it has been used for writing or sketching.
} 
over a pulley and from which a circular weight is suspended. The three blocks are shown superimposed in two different orientations: stacked vertically and lying horizontally. Very faintly but distinctly, we can see the line of the string extending from the bottom block of the vertical stack. Below this diagram and overlapping it are more sets of blocks aligned in vertical and horizontal patterns: this time there are eleven horizontal blocks and perhaps ten vertical, but their drawing is smudged and indistinct, and the bottom of the vertical stack lies below the horizontal row of blocks. The number ' 10 ' is written above this horizontal line of blocks. Below these blocks there are two sketches of isosceles triangles with the apex truncated; superimposed on the right-hand one is a rectangle. In both cases the triangles are bisected by a vertical line. And written firmly in the same chalk across the centre of the page, partially obscuring the main diagram of the blocks and pulley, is the statement ' $l a$ confregazione si fa di duplicata fatica in duplicato peso': 'friction is of double the effort for double the weight'.

Here we have not only an unequivocal statement that the force of friction is proportional to the applied load, but also a sketch of an experiment. It could be an experimental arrangement for testing the hypothesis that the force of sliding friction is independent of the apparent area of contact, or it could be a statement in pictorial form that that hypothesis is true. Whichever is the correct interpretation, this sketch indicates that Leonardo at least strongly suspected at this time that friction was independent of contact area. The additional sketches of the lines of ten or eleven blocks suggest that he felt it was also true for different weights as well. Leonardo repeated this crude diagram of the sets of blocks in a much clearer format soon afterwards, as shown in Fig. 3 (Madrid I 173v, c. 1493-7), accompanied by a definitive written statement about the effect of contact pressure on friction: 'you will find such effort in the motion made by small and heavy contact, as in that made by a large and light contact'. 


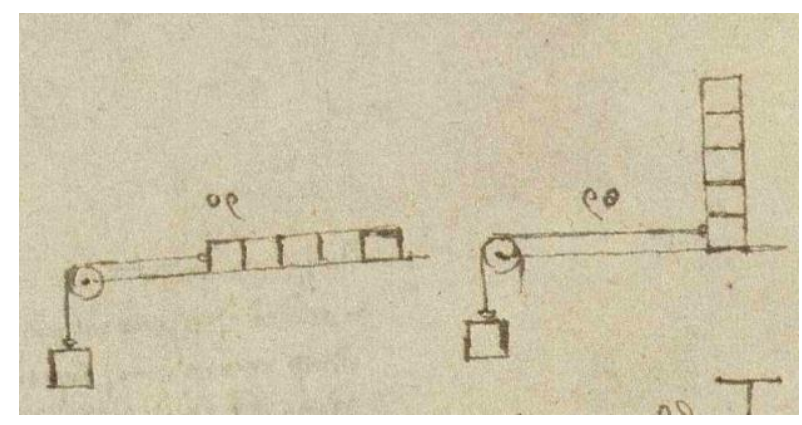

Fig. 3. Sketches illustrating the effect of contact pressure or contact area on friction (Madrid I $173 v$, c. 1493-7, Biblioteca Nacional, Madrid)

The triangular diagrams at the bottom of the page in Fig. 2 might appear at first glance to be unrelated to the sketches on friction, but they are geometrical representations of the concept of proportionality frequently used by Leonardo in other contexts: his 'pyramidal law'. Leonardo applied this method to visual perspective, the speed and time of fall under gravity, and the fading of sound with distance [5, 38]. Here he uses the triangles, bisected to create pairs of similar triangles one twice the size of the other, to illustrate the proportionality of friction to weight: as the weight is doubled (i.e. for a triangle of twice the length) the friction force (represented by the vertical line forming the base of each isosceles triangle) is also doubled. Although Leonardo may only have intended these triangles to illustrate the principle of proportionality, it is nevertheless possible to deduce from each of them a rough value for the ratio of the friction force to the weight or normal force: what we would nowadays call the coefficient of friction. For the two diagrams, if we assume that the sides of each truncated triangle are extended to form an acute apex, these ratios are $1 / 2$ and 1/3. We can also derive a value for the coefficient of friction from other information; immediately above the top of the vertical stack of three blocks, overwritten with the word 'bella' in pencil is the number ' 5 ' in red chalk, and immediately beneath the hanging weight is the number ' 2 ', which suggests a value of $2 / 5$. 


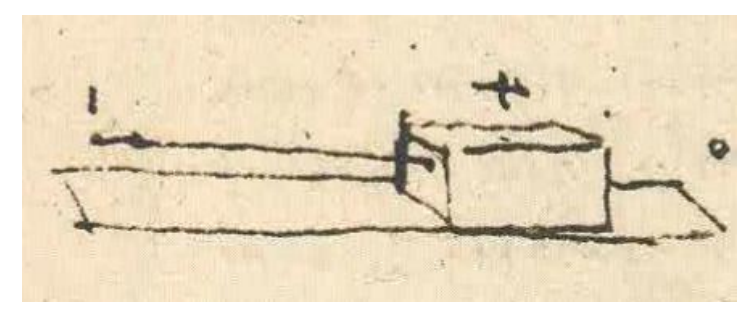

Fig. 4 Sketch illustrating a block being pulled along a plane. The weight of the block is 4 units and the traction force is one unit. (Forster II 124v, c. 1497)

Over the next few years, Leonardo repeated and expanded his statements about the friction of bodies sliding on horizontal surfaces, but also considered both rotational sliding (for example the rotation of a shaft in a plain bearing, which he correctly regarded as analogous to sliding on a plane) and rolling motion. He began to make explicit statements about the value of the ratio between friction and weight. At one point in Codex Madrid I he writes 'the force used in the sliding movement over the horizontal plane is always half the weight of its movement' (Madrid I 176r, c. 1493-7), while elsewhere in the same notebook at about the same date he assumes a value of one third for the friction between a sliding block and a plane (Madrid I 73r, c. 1493-97). He also uses a ratio of one third in calculating the friction on a wheel axle (Madrid I 122r, c. 1493-7), but on another page repeatedly implies that the ratio is one eighth for blocks sliding on planes (Madrid I 74r, c. 1493-7). Soon afterwards he starts to use a value of one quarter. For examples, in Forster II 124v (c. 1497) he draws a block being dragged along a plane (Fig. 4). He writes a number '4' above the block, and ' 1 ' by the string, and states 'for every sliding weight the quarter part of its gravity is that which gives effort to its movement': a clear quantitative statement that the coefficient of friction is $1 / 4$.

By 1500 Leonardo had arrived at a rather more consistent but also more sophisticated picture of sliding friction. At least 16 times between 1500 and 1515, he either made statements that the ratio of friction to weight was one quarter, or used that value in 
calculations $^{7}$ and did not mention any other value. But he had also realised before 1497 that the nature of the surfaces in contact affected friction, as well as the presence or absence of material (including lubricants and rolling elements) between the surfaces. He wrote '...... different bodies have different kinds of friction; because if there shall be two bodies with different surfaces, that is that one is delicate and smooth and well-greased or soaped, and it is moved upon a plane of a similar nature, it will move much more easily than one that has been roughened by the use of file ${ }^{8}$ or rasp' (Forster II 87r, c. 1497); and 'everything however thin that is interposed between objects that rub together lightens the difficulty of the friction. Observe the friction of great weights, which make rubbing movements, .... the larger the wheel that is interposed, the easier this movement becomes; and so also conversely the less easy as the intervening thing is thinner as would be any thin greasiness; and so tiny grains like millet $^{9}$ make it better and easier, and even more balls of wood or rollers, that is cylindrical wheels, and as these rollers become larger so the movements become easier'. (Forster II 132r, c.1497). He made a general statement in Codex Madrid I (65r c.1493-7): 'the frictions of heavy bodies will be of such varied effort as their causes, as the surfaces of the bodies in contact vary.'

Subsequently (CA 525r, c. 1500) he provided a list of combinations of properties of the moving body and the plane: hard on hard, hard on soft, soft on hard, rough on smooth, smooth on rough, rough on rough, smooth on smooth, concluding with the notes: 'rough and hard with rough and hard - movement of the greatest difficulty; rough and soft with rough and soft - medium difficulty'. He repeated his thoughts on the effects of small particles (such as

\footnotetext{
${ }^{7}$ CA 525r, Arundel 187r, CA 438r, CA 438v, CA 910v, Madrid II 46r, CA 261r, CA 532v, CA 539v, CA 58r, CA 198r, CA 311r, CA 732v, CA 961r, CA 558r, CA 864r.

${ }^{8}$ MacCurdy [21] translates 'lima' as 'lime', but from the context the alternative meaning of 'file' is clearly more appropriate.

${ }^{9}$ Muendel [39] has suggested that Leonardo actually used millet seeds as a lubricant additive, but this seems implausible; it is more likely that he was commenting on the possible benefits of adding small round particles shaped like millet seeds, as he also did in CA 525r.
} 
stones) in the contact; if they were rounded in shape, the motion would be easy, and would be easier still if they were large and round. In some of Leonardo's later statements that the coefficient of friction is one quarter, he also specified that the surfaces should be 'smooth' (CA 532v, c. 1507) or 'dense and smooth' (CA 198r, CA 311r, CA 732v, all c. 1508). Even later he made further comments that friction varies according to where it occurs, that is, whether the bodies are rough or smooth (MS E 54v, c. 1514).

While in his statements on friction he generally did not specify the materials involved, in one case Leonardo was quite specific in identifying an exception to his general rule that friction does not vary with the contact area. In CA 198r (c. 1508), after reiterating the general rules that smoother surfaces have the lowest friction, and that the apparent contact area does not affect friction, he notes the case of a surface that is rough and compliant: 'for a body of unequal sides and uniform flexible roughness, the friction made by its larger side will be of greater potential. Proof. If the particle of the flexible roughness, like corded cloth (panno corda) or similar, resists like one (unit), it is necessary that 4 particles resist like 4 and 100 like 100. But if the one is loaded with a greater weight, this particle bends and the body which is sliding no longer has this particle which impedes it, by being bent and folded and having no resistance.' What Leonardo is telling us here is that for this special case of rough cloth, the very compliant asperities will deform under high contact pressure, so that the friction force is no longer independent of apparent contact area; the coefficient of friction will fall as the pressure increases. Although he does not explicitly mention it, this is consistent with his earlier observations on the ease of dragging a rope over the ground (see footnote 5). 


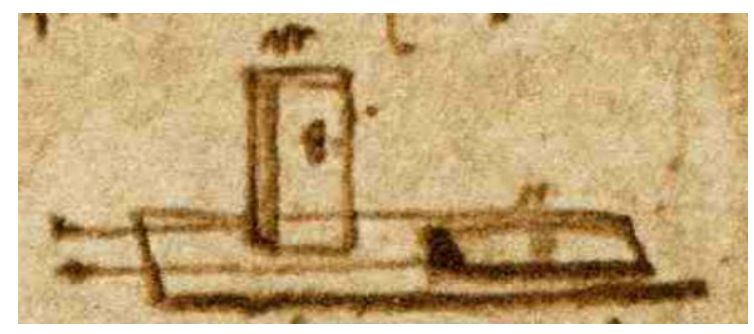

Fig. 5 Sketch showing a block of weight 8 units sliding in two different orientations labelled $m$ and $n$ (CA 198r, c. 1508)

On the same page he illustrates the variation of pressure with a sketch (Fig. 5) showing a single block weighing 8 units in two orientations, and attempts to evaluate the difference in the contact pressure: 'this body is 4 eighths long and 2 wide and 1 thick. Thus it follows that $n$ rests with $8 / 8$ and $m$ rests with $2 / 8$ and each eighth supports $4 / 8$ and in $n$ each eighth supports 1/8.' Our understanding of this convoluted statement is not assisted by Leonardo's use of the unit of 'eighths' (ottavi - perhaps of a braccio) for both lengths and areas, and also eight units (probably libbre - 'pounds') for the weight of the block, and his reasoning is not easy to follow, but he does end up with the correct conclusion that block $m$ exerts four times the pressure (load per unit area) of $n$. The information he provides about the weight and dimensions of the block allows us, if we make some assumptions about the units used, to estimate its density. Different units of length and mass were in use in different regions of Renaissance Italy. Leonardo commonly used the braccio as a unit of length. While this is often taken $[5,40]$ to be close to 24 imperial inches (= $0.61 \mathrm{~m})$, Zupko [41] suggests more precisely that the Florentine braccio was $0.584 \mathrm{~m}$, while that used in Milan was $0.595 \mathrm{~m}$; the libbra was $0.339 \mathrm{~kg}$ in Florence and $0.327 \mathrm{~kg}$ in Milan. These data taken together suggest a density for the block in range of 740 to $870 \mathrm{~kg} \mathrm{~m}^{-3}$, values which are not far from the densities of many woods (e.g. European oak, ash and beech all have densities of $720 \mathrm{~kg} \mathrm{~m}^{-3}$ [42]) and suggest that the block was very probably of wood, and certainly not of stone or iron. 
Leonardo's attempt to list the effects of possible combinations of surface roughness and hardness is one example of his general determination to classify and provide order to the natural world [5]. He also discriminated between various characteristics of the contact geometry and relative motion in the context of friction, which he described as 'simple' or 'compound' (composto) in several different ways. He applied this distinction between simple and compound in other areas as well: for example, to the movement of solid bodies (e.g. MS K 107r, Arundel 140v) and of water (MS F 72r, MS K 60v), and the shadows cast by objects (CA 258r).

He described his first method of classifying friction as follows (Forster II $131 \mathrm{v}$, c. 1496): 'The action of friction is divided into parts of which one is simple and all the others are compound. Simple is when the object is dragged along a plain smooth surface without anything intervening; this alone is the form that creates fire when it is powerful, that is it produces fire, as is seen with water-wheels when the water between the sharpened iron and this wheel is taken away. The others are compound and are divided into two parts; and the first is when any greasiness of any thin substance is interposed between the bodies which rub together; and the second is when other friction is interposed between this as would be the friction of the axles of the wheels. The first of these is also divided into two parts, namely the greasiness which is interposed in the aforesaid second form of friction and the balls and things like these.' He subsequently attempted to classify friction according to the number of 'levers' operating: a single 'lever', as for a body sliding over a plane, gave 'simple' friction, while multiple 'levers' gave 'compound' friction CA 525r, c. 1500). The concept of a 'lever' appears repeatedly in Leonardo's mechanics and often relates to the straightforward idea of an arm of a balance (which would be held in equilibrium by a weight acting on a 'counterlever'), but in other cases the meaning is more obscure. In a third example, from 1514, he classified friction as 'simple', 'compound', and 'decomposto', which MacCurdy [21] translates as 
'irregular': 'simple friction is that made by the moving body upon the place where it is dragged. Compound is that which the moving body makes between two immovable bodies. Irregular is that made by the wedge of different sides' (MS E 35r, c. 1514). The accompanying diagram (Fig. 6) suggests that friction was 'decomposto' when the normal forces giving rise to friction were applied in more than one direction.

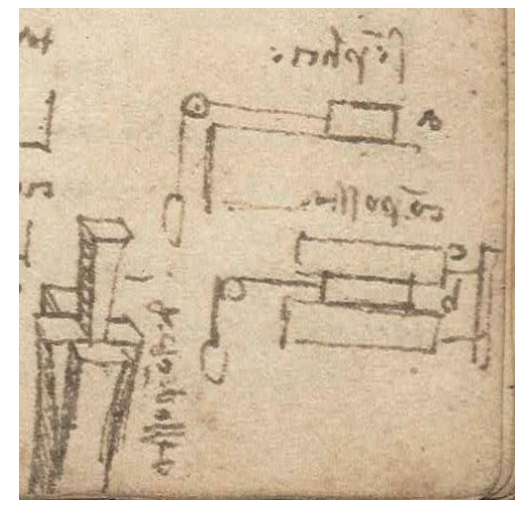

Fig. 6 Sketches illustrating one way of classifying friction: simple, compound (composto), and decomposto (MS E 35r, c. 1514, Bibliothèque de l'Institut de France, Paris)

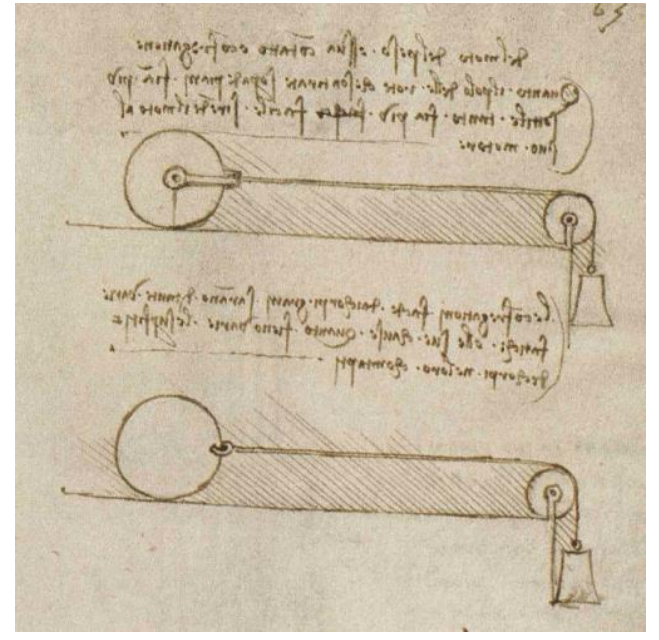

Fig. 7 Sketches showing bodies rolling and sliding on horizontal planes (Madrid I 65r, c. 1493-7) 


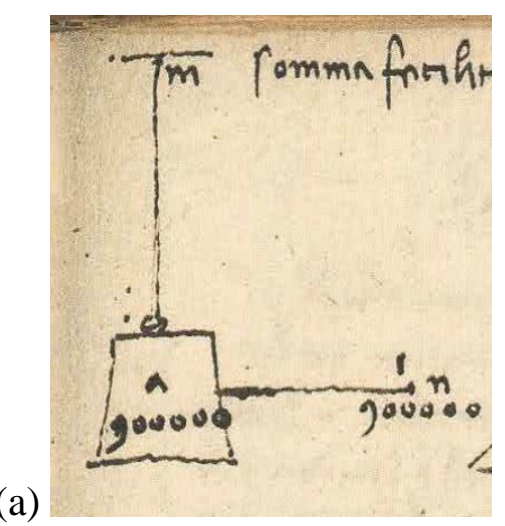

(b)

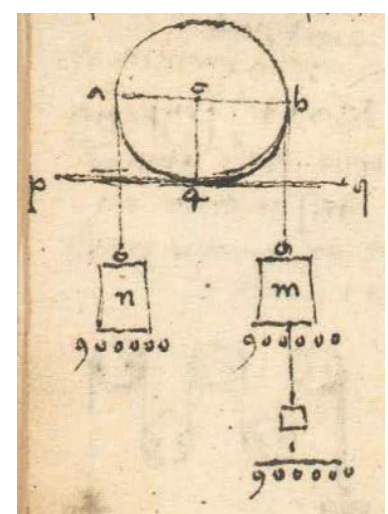

Fig. 8 Sketches illustrating an analogy between the very small force needed to displace a hanging weight sideways and that needed to cause rolling (Forster II 124v, 125r, c. 1497; images reflected for clarity)

From around 1493 onwards, Leonardo also recorded notes on rolling friction. In some cases these were accompanied by simple sketches to compare sliding and rolling motion, as shown in Fig. 7 (Madrid I 65r c. 1493-1497, MS L 84v c. 1497-1502). But elsewhere he attempted to explain why the frictional force was much smaller for rolling than for sliding. In the diagrams shown in Fig. 8 (Forster II 124v and 125r, c. 1497) he draws a suspended weight being moved sideways by a string, as well as a circular object being rolled over a plane, and writes 'if $p q$ is perfectly flat, and similarly the circle $a b d$ is perfectly round, it is certain that their contact will be at a point, above which point this circular body balances with equal weight, so that an almost infinite magnitude of weight will be moved by an almost infinite smallness of weight....' Although the words may not be as clear as we might like, the diagrams tell the story perfectly. Leonardo is saying that even if the load on the circular body is enormous, symbolised by the weights of 900,000 units hanging on each side, it will be perfectly balanced over the point of contact. It will take only a tiny additional force, represented by the extra 1/900,000 units on one side, to cause the body to roll. He draws an analogy with the displacement of the hanging weight, saying that even if that is immensely heavy (900,000 units), it takes only a very small force (of 1/900,000 units) to cause it to move sideways. His treatment of the problem of rolling contact not only shows his early thinking 
about rolling friction, which he extends later, but also illustrates how he treated numbers. The precise value of the number 900,000 is not important, but acts as a symbol for a 'very large number'; similarly $1 / 900,000$ is 'a very small number'. Leonardo is not telling us here that he has measured the coefficient of rolling friction, but he is telling us that, in contrast to the case of sliding, it is very, very small.

\section{Applying the rules}

Leonardo's attention and interest were captured by many examples of mechanical systems in which friction played a role. Sketches of machine elements and mechanisms are pervasive in his notebooks. In particular, he studied balances and levers, pulleys and wheels, inclined planes and screws, not only because as a military engineer, architect and sculptor his work involved the transport and positioning of heavy weights, but also out of a desire bordering on the obsessive to understand the rules which governed their operation. These systems could be analysed most simply by ignoring friction, which Leonardo did also in some cases, but he knew that friction was important in limiting the efficiency and precision with which these devices operated, and he endeavoured to incorporate friction into his understanding with a dogged determination.

\subsection{Rotational sliding friction: cart wheels and axles}

Even before his earliest recorded statement on sliding friction (Fig. 2), Leonardo had noted that wheels rotating on fixed axles of small diameter rolled with lower resistance than ones with larger diameter axles. He used a sketch (Fig. 9) to compare the behaviour of two wheels with different-sized axles (CA 561r, c. 1487-90), but gave an incorrect explanation for his observation based on the effect of the distance from the ground to the bottom of the axle. 


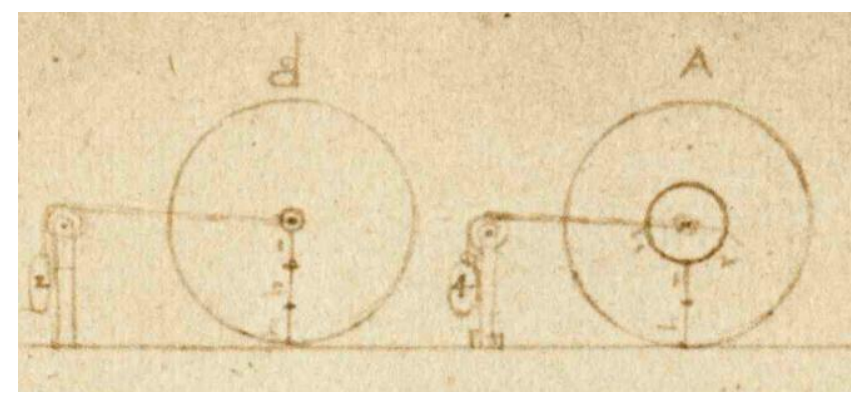

Fig. 9 Diagram comparing the forces needed to roll wheels with axles of different diameters (CA 561r, c. 1487-90)

(a)

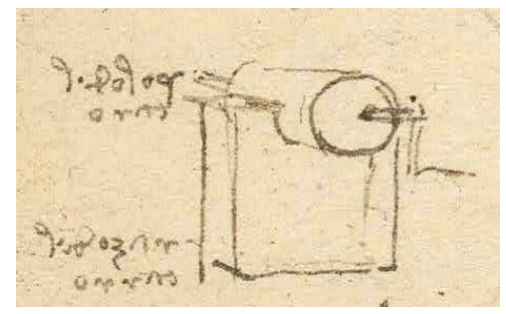

(b)

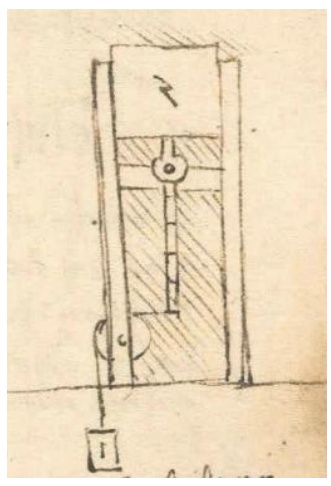

Fig. 10 Sketches suggesting methods to measure the torque on rotating axles: (a) from MS B 99r, c. 1487-90; (b) from Forster II 111r, c. 1497.

At about the same time he designed a cart supported on wheels with multiple thin axles, writing: 'this is a cart very easy to pull, but make the axles thin' (MS B 99r, c. 1487-90) ${ }^{10}$. By this point he had realised that the bearing on which the wheel rotated was the source of the resistance, and he also sketched an idea for a method to demonstrate the effect for an isolated axle and its bearing (Fig. 10a): 'how to prove that the slender axle is easy. Take account that the axle may be of 30,000 pounds, how (if) the contact is large the weight increases'. But his sketch does not show how such a heavy load might be applied to the axle, nor how the ease of rotation might actually be measured. Although he did not state it explicitly, he was trying to understand the effect of friction in journal bearings.

\footnotetext{
${ }^{10}$ There are also notes and sketches relating to the ease of motion of carts elsewhere in MS B (folios 33v, 51r, $76 \mathrm{v}, 77 \mathrm{r}$ and $92 \mathrm{v})$.
} 
Within a few years he had understood that the ratio between the wheel diameter and the axle diameter was the important factor, although he still did not explicitly mention friction: 'between wheels of equal diameter that with the easier movement is that supported on the thinner axle. It is clear that the wheel has easier movement for which the diameter of its axle divides more times into the diameter of the wheel.' (CA 1015v, c. 1493-5). He soon made a more definite statement: 'the frictions which the axles make in the concavities which receive them are the cause that renders them difficult to turn.' (CA 421v, c. 1495-7). And at about the same time he was sketching a much more ingenious experiment (Fig. 10b). The large weight at the top of the diagram provides a downward force on the bearing which is supported on a thin fixed axle. The force needed to rotate the bearing is transferred from the suspended weight by the string attached to the vertical lever arm, which is marked to indicate that its length would be known. He notes 'by this it is proved that the thinner the axle the cart has, the easier is its motion' (Forster II 111r, c. 1497), but he does not provide an example of how he might analyse the results of this experiment. At about the same time, he was musing on the difference, if any, between rotational and linear sliding: 'what difference is there between the circular friction of axles and the linear ('direct') friction of things which are dragged?' (MS I 113v, c. 1497).

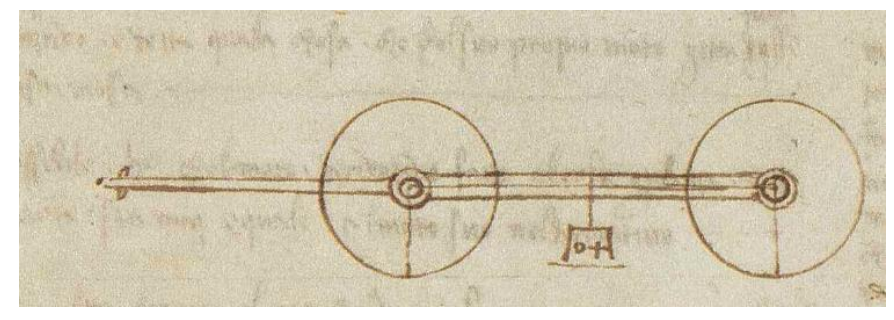

Fig. 11 Sketch showing a cart for which Leonardo analysed the effect of friction on the axles (Madrid I 122r, c. 1493-7)

As Leonardo's understanding developed, he moved from qualitative comments on the effect of axle diameter to quantitative treatment of practical cases. He took the example of the 
cart shown in Fig. 11 (Madrid I 122r, c. 1493-7), where the diameter of the wheels is forty times that of the axles. He then correctly deduced that forty pounds of friction on the axle surface will require one pound of traction to move the cart. Forgetting that the 40 pounds of friction will originate from a rather greater weight on the axles, he then compared the one pound needed to move the cart with the wheels rotating with the force needed to drag it if the wheels were fixed: he assumed a coefficient of friction of $1 / 3$ and correctly concluded that in this case to drag a weight of 40 pounds, $131 / 3$ pounds would be needed.

Within a few more years (CA 525r, c. 1500) he analysed the problem of the wheel of an artillery wagon, 21/2 braccia (about $1.5 \mathrm{~m}$ ) in diameter with an axle diameter of $1 / 4$ braccia (about $150 \mathrm{~mm})^{11}$. He assumed that the axle carried a load of 8000 pounds (about 2.7 tonnes). After an initial abortive attempt to calculate the force needed to move the carriage (for a single wheel) he started afresh, writing: 'I find 10/8 against $1 / 8$, that is 10 of lever and one of counter(lever). Thus one in the lever is against 10 in the counterlever. Then use the rule of three, and so if one is against 10, what will be against 8000, which has 2000 of friction? Do (this) and you will see that there are 200 pounds of potential, which is the friction of 800 pounds dragged over the ground.' He treated a similar case with more assurance a few years later (Madrid II 46r, c. 1503-5), where the wheel diameter was 24 times that of the axle, which this time he specified as being of iron. He assumed a load of 96 pounds: 'Then the friction of the weight placed over the part of the hole of the wheel being the quarter part of the weight, the 96 pounds become 24. And by the lever of the wheel, that is 24 against one, you will have one pound against 24 pounds. So one pound of potential will pull 96, and this may be the foundation of the rule by which you can, with the rule of three, know the potential which you need to move any weight. So if we have to move 6000 pounds, by the above rule:

\footnotetext{
${ }^{11}$ From the dimensions of this axle we can assume that it was probably made from wood.
} 
if 96 is against one, what will be equal to 6000? Use the rule of three and you will find that on level ground 6000 will be against $62 \frac{1}{2} 2$. In both these cases, Leonardo assumed a coefficient of friction of $1 / 4$.

These two examples, which led to correct answers ${ }^{12}$, illustrate aspects of his methods of analysis which are repeated throughout his notebooks, not only in treating problems of friction but in other fields as well. He frequently draws analogies with the properties of the lever with which he is very familiar, but expresses its behaviour in terms not of moments of forces, but of ratios of forces in inverse proportion to the ratios of distances (the lengths of the 'lever' and 'counterlever') $)^{13}$. His examples use weights and distances that are often multiples of four, which lend themselves to simple calculation. To generalise his results he uses the 'Rule of Three', even where, as in the first example, it is obvious to us that he simply needs to divide by ten. ${ }^{14}$

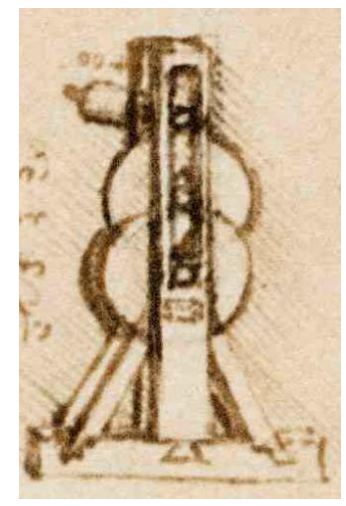

Fig. 12 Stack of three rollers for which Leonardo calculated the force required on the top roller to overcome the friction at the bearing of the lower roller. (CA 961r, c. 1508)

\footnotetext{
${ }^{12}$ In fact, the method used by Leonardo is not perfectly accurate, but the error is negligible for these ratios of wheel to axle diameter.

${ }^{13}$ Researchers have argued over Leonardo's understanding of the concept of the moment of a force [23, 24, 25]. There is certainly at least one place (Arundel 1r) where he does calculate the product of a force and a lever arm, but this is an isolated occurrence and his general approach elsewhere is always to employ a more complicated method involving inverse proportionality.

${ }^{14}$ The Rule of Three is a simple, formulaic method for calculating the effect of scaling up a quantity by a given ratio, widely used before and during Leonardo's time [43]. In algebraic terms, if we know that $a: b:: c: d$, then the Rule would state that $d$ is found by multiplying $b$ by $c$ and dividing by $a$, so that $d=b c / a$.
} 
By 1508 Leonardo had the confidence to attempt more complex problems of rotational friction, such as in the stack of three rollers seen in Fig. 12 (CA 961r, c. 1508). Here he correctly evaluated the gearing effect of each wheel/axle contact, so that the friction exerted on the lower axle (for which he assumed the coefficient of friction was $1 / 4$ ) could be overcome by a proportionally much smaller force on the uppermost cylinder. This concept was not new to him; some ten years earlier he had sketched cascades of eight (MS I 114r, c. 1497-9) and no fewer than 24 wheels coupled in the same way (Madrid I 103r, c. 1493-7), but without explicitly calculating the friction.

\subsection{Rotational sliding friction: other applications}

Leonardo's success in analysing the effect of friction between cart wheels and axles with his limited mathematical resources resulted from the simplicity of the problem: the net force on the wheel due to the weight of the cart and the friction at the axle remained very close to vertical, and thus almost orthogonal to the force applied to drag the vehicle over the ground. In studying rotational friction in other systems, however, he encountered more challenging problems, in which the force acting normal to the bearing surface is significantly modified by the action of friction. The isolated cylindrical shaft in a half-bearing shown in Fig. 13a illustrates the issue (CA 1015v, c. 1493-5). Leonardo assumes that the shaft weighs 100 pounds and that a 'counterweight' of 100 pounds should make it rotate. He becomes frustrated in trying to make sense of it, commenting: 'it is wrong, because the axle and the counterweight together weigh 200 pounds and a quarter of 200 is 50 . Thus 50 pounds will move 200.' But he has just postulated that he needs 100 pounds to overcome the friction rather than 50, and he cannot resolve the inconsistency. 
(a)

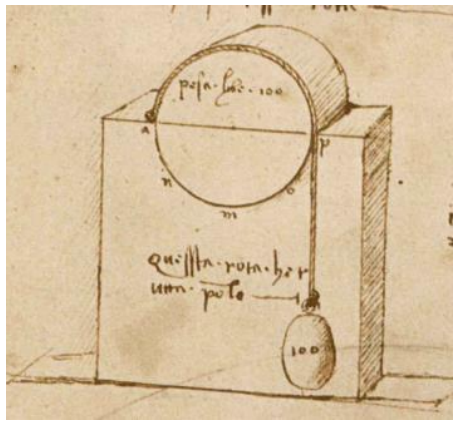

(b)
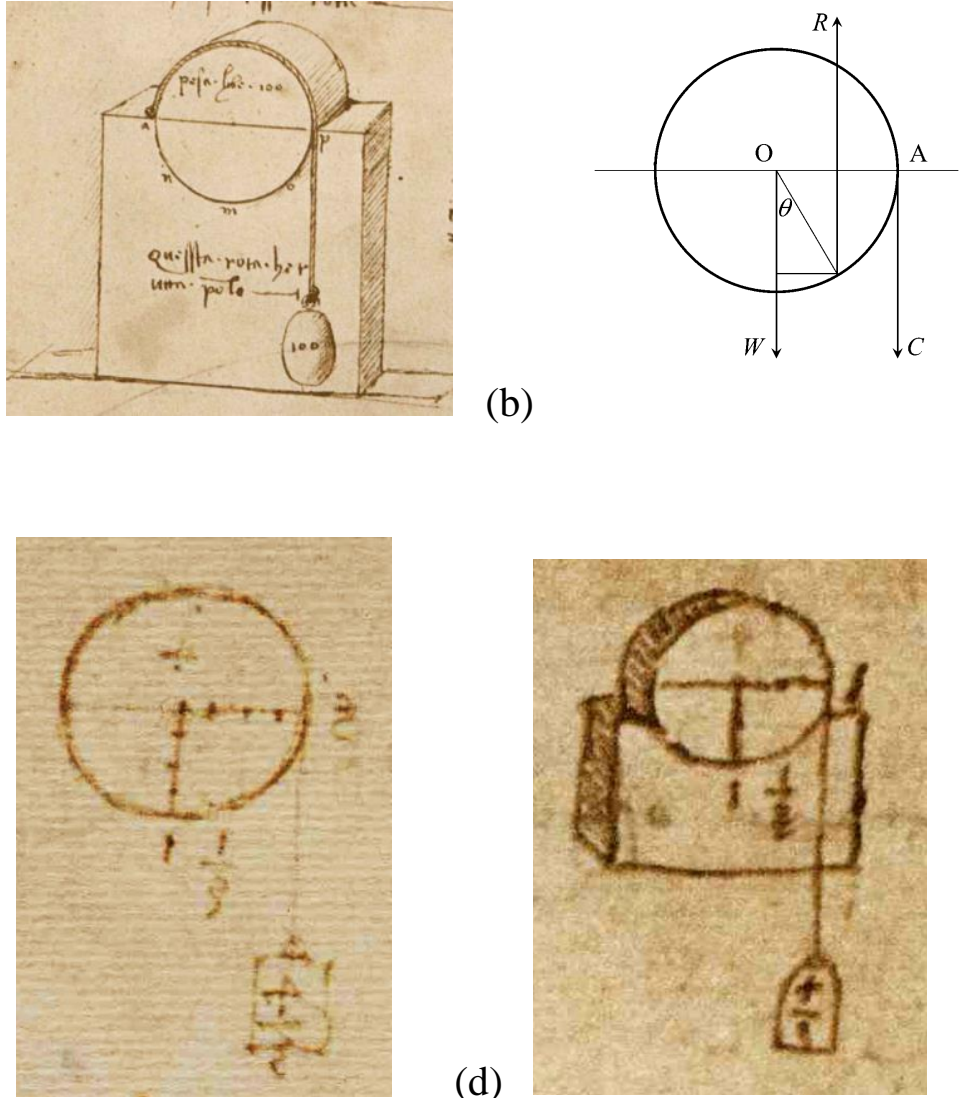

(d)

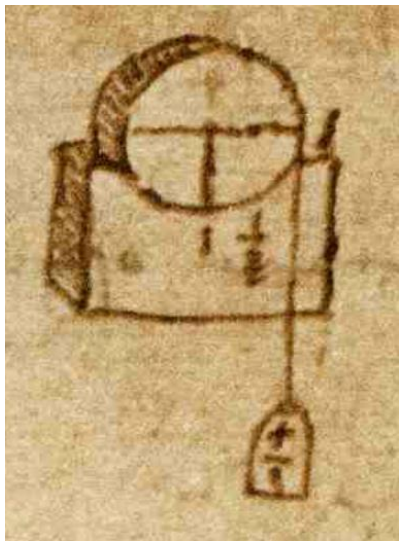

Fig. 13 (a, c, d) Sketches showing a cylinder supported in a half-bearing, carrying a hanging weight. Image (a) has been reflected for consistency with the other diagrams. (CA 1015v, CA 910v, CA 198r). (b) Forces acting on the cylinder in a two-dimensional version of the problem.

By drawing the force vectors for a two-dimensional version of the shaft we can see why he found the problem difficult (Fig. 13b). The weight $W$ and the counterweight $C$ both act downwards. Equilibrium demands that the reaction force from the bearing $R$ must also be vertical, and in this case (for $C=W$ ) must bisect the line OA. If the counterweight changes, then the point of action of $R$ will shift, and its component normal to the bearing surface will change. The general relationship between $C$ and $W$ for this system at the point of sliding, and with a coefficient of friction $\mu$ where $\mu=\tan \theta$, is given by: 


$$
C=\frac{W \sin \theta}{(1-\sin \theta)}
$$

If $C=W$ it can readily be shown that $\mu=0.577$, and not the value of $1 / 4$ which Leonardo had assumed.

Leonardo continued to pursue this problem for several years but eventually reached a consistent and satisfactory solution. Figure 13c shows a diagram from 1502-3 (CA 910v), and Fig. 13d is a similar sketch of a few years later (CA 198r, c. 1508). Numerous similar sketches are to be found on other folios of the Codex Atlanticus dated between 1502 and 1508. The cylinder weighs 4 pounds, and Leonardo clearly explains his reasoning in choosing a counterweight of $4 / 3$ pounds to balance the friction: 'See that I have here 1 , which is for the friction of the axle which is (i.e. weighs) 4 , and again I have $1 / 3$ which is the friction of the weight of the counterweight which is $4 / 3$, which is loaded on the axle. Thus the proof is good, because 1 and $1 / 3$ are $4 / 3$ and are equal to the counterweight of the friction, which is 4/3. A second proof confirms it again, because the 4 of the weight combined with $4 / 3$ of the weight of the counterweight make $16 / 3$, of which weight the friction is a quarter, that is $4 / 3$.' The fact that his 'proof' starts with an assumption about the size of the counterweight suggests that Leonardo probably arrived at his answer by trial and error, and there is ample evidence from other sketches that he tried many different combinations of weight and counterweight before settling on the satisfactory combination shown here. We can express his method in terms of the symbols defined in Fig. 13b: he is saying that $W / 4+C / 4=C$, and hence that $C=W / 3$. For comparison, the accurate solution given by equation (1) for $\mu=0.25$ is $C=0.32 W$. Leonardo's method thus turns out to be remarkably accurate, but only because the friction is rather low. For a general value of $\mu$ his method gives $\mu(W+C)=C$, from which: 


$$
C=\frac{W \tan \theta}{(1-\tan \theta)}
$$

For $\mu=0.5$, Leonardo's method would predict that $C=W$, whereas the accurate solution of equation (1) gives $C=0.81 \mathrm{~W}$.

(a)

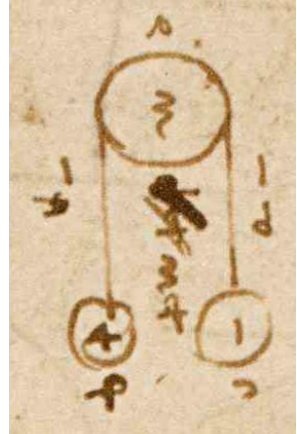

(b)

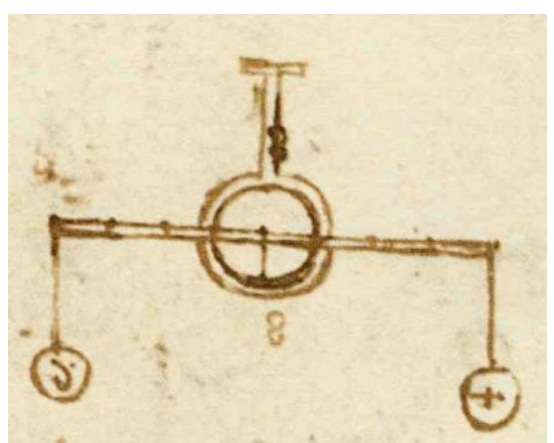

Fig. 14 Sketches showing (a) a heavy rotor with two suspended weights (CA 972r, c. 14991500) and (b) a balance with friction on a large-diameter axle (CA 438r, c. 1500-5)

In attempting to account for rotational friction in other configurations Leonardo was less successful. Two examples are shown in Fig. 14: a rotating shaft carrying suspended weights on both sides, sometimes acting on one or two lever arms extending horizontally from the shaft (e.g. CA 972r, c. 1499-1500, CA 417v, c. 1508-10), and essentially the same problem expressed as a balance with friction at the central bearing (CA 210r, c. 1495-7, CA 438r, c. 1500-5). These problems recurred repeatedly in his notes between about 1495 and 1510, especially in the period 1506 to 1510 . He struggled to analyse the effect of friction, trying to use a similar approach to that for the rotor with a single attached weight (Fig. 13), but erroneously adding frictional contributions to both sides of the rotor. At one point (CA 
438r, c. 1500-5) he suggested that a precise solution is not possible, explaining that the extra weight added to overcome friction then requires additional weight to overcome the additional friction caused by the additional weight, and so on ad infinitum. Elsewhere he had tried, and failed, to carry through such a calculation, making several errors and being unable to sum the resulting geometric series (CA 972r c. 1499-1500). Had he persevered with this approach it would have provided an additional and convincing method to solve the problem of the rotor with attached weights.

\subsection{Sliding friction on a plane}

Quantitative treatment of problems involving a body sliding on a plane in which its weight acts in combination with friction presented an insuperable challenge to Leonardo who was working without the basic concepts of Newtonian mechanics that would be developed 200 years later. In some cases, he could state the problem but make only qualitative comments about the solution. Fig. 15a (MS G 91r, c. 1510-15, see also CA 539v, CA 514r, c. 1506-8) shows an example. He writes: 'Ask which cord moves the beam $n h$ more easily, and how easily? $a$ does not move it but only lifts, $c$ lifts and moves, and so does $d$, and $e$ does it more easily. The best is $f$.'

(a)

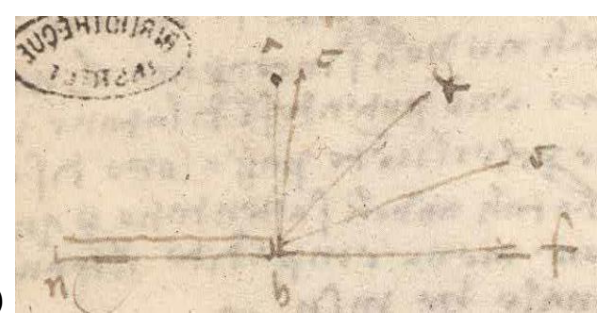

(b)

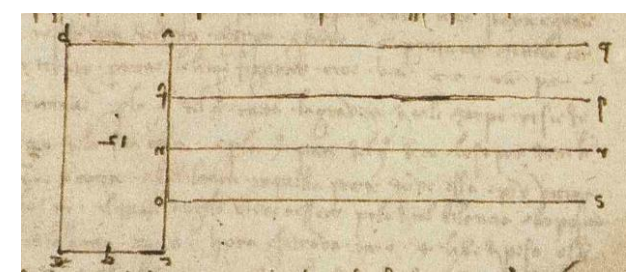

Fig. 15 Sketches showing (a) a horizontal beam resting on a plane, being pulled by cords at various angles (MS G 91r, c. 1510-15, image reflected for clarity) and (b) a block being pulled by cords attached at various heights (Madrid I 73r, c. 1493-7) 
In other problems he attempts to apply the principle of the lever, as in Fig. 15b (Madrid I 73r, c. 1493-97) where he asks which of the four strings will cause the block to tilt about point $c$ rather than slide. Here he assumes that the friction is one third of the weight of the block. He compares the length $o c$ (the lever) with $c d$ (the counterlever) and concludes correctly that the block will slide when pulled by the lower string. He even notes that this will cause the base to be unevenly loaded against the plane (which will occur whenever the string is attached at any point above the bottom surface). Unfortunately his subsequent notes are truncated, and we cannot follow his further thoughts. Examples of analogous problems on the following pages (Madrid I 73v and 74r) where the cords are pulled at an angle show him confused about how to incorporate friction and unable to reach a full understanding. Fig. 16 provides a further example. Leonardo correctly takes the point $m$ as the centre of gravity of the mass and $n$ to be the axis of a balance, the arms of which are the lines $r n$ and $n m$. He then effectively takes moments about $n$, with 16 pounds from the suspended weight acting at the end of $r n$, but incorrectly takes 8 pounds to act at the end of $n m$. Making an implicit assumption that the coefficient of friction is $1 / 8$, he adds one pound of friction to the 16 pounds from the weight, and concludes that he needs 17 pounds and a little more at $\mathrm{X}$ to cause the block to slide. Another erroneous treatment of friction in a similar problem occurs in CA 617r (c. 1499-1500).

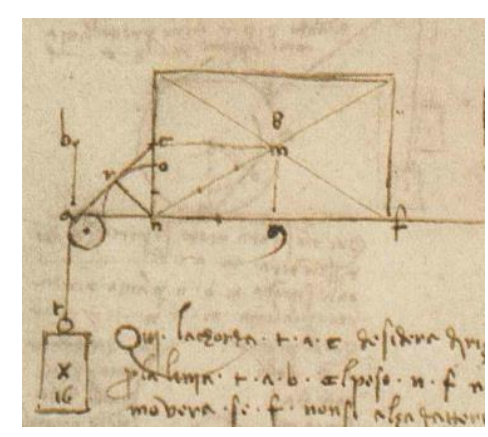

Fig. 16 Sketch of a block resting on a plane and being pulled by a cord passing over a pulley with a hanging weight (Madrid I 74r, c. 1493-7, image reflected for clarity) 
Leonardo's earliest sketch relating to the problem of a mass on an inclined plane (Fig. 17a, c. 1493-4) was unaccompanied by any words, but shows circular bodies in four different positions: on a horizontal plane, beside a vertical plane, and on two planes at intermediate angles of about $30^{\circ}$ and $60^{\circ}$ to the horizontal. From his comments associated with similar but later diagrams (e.g. Arundel 187r, MS L 26v) it is clear that the numbers indicate the force needed to pull the weight along the plane: 12 vertically, $1 \frac{1}{2}$ horizontally (corresponding to a coefficient of friction of 1/8) and 6 and 3 at the intermediate angles. At about the same time he wrote: 'of the friction between bodies of the same weight and roughness, that which is more horizontal is more difficult. And conversely, that which is more oblique will be easier.' (Madrid I 139v, c. 1493-7). He drew the powerful analogy between the movement of a weight on a slope and the action of a screw thread, illustrated by the elegant drawings of Fig. 18 (Madrid I 86v, c. 1493-7) and also sketches and notes in Forster III 81v (c. 1493-4). He subsequently wrote: 'whoever knows how great a weight raises the hundred pounds upwards by this slope knows the capacity of the screw' (Forster II 87r, c. 1497).

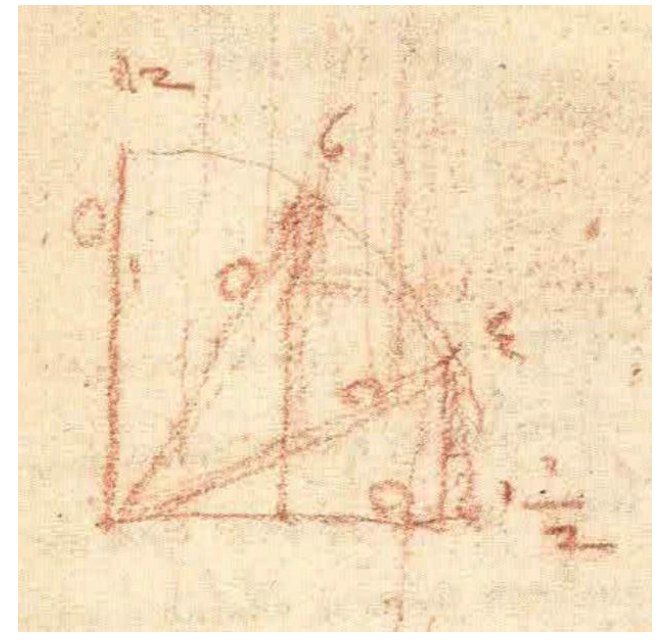

(a)

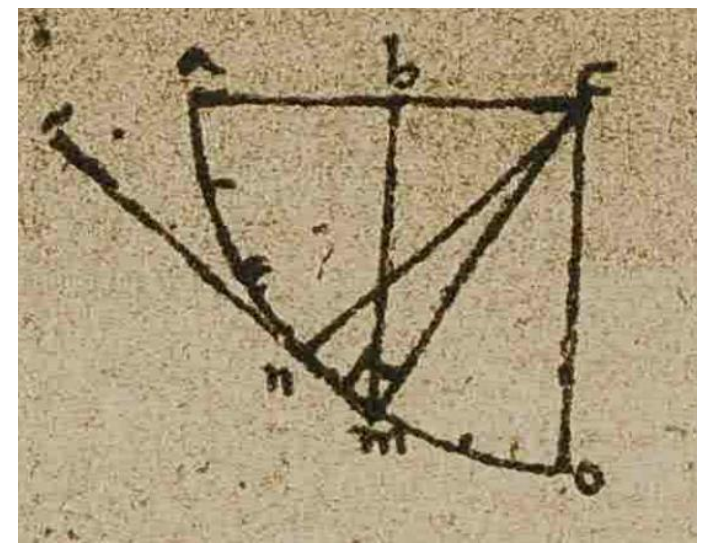

(b)

Fig. 17 Sketches showing masses being pulled along inclined planes at various angles: (a) from Forster III 81 r, c. 1493-4 (image reflected for clarity); (b) from Arundel 187r, c.150005 


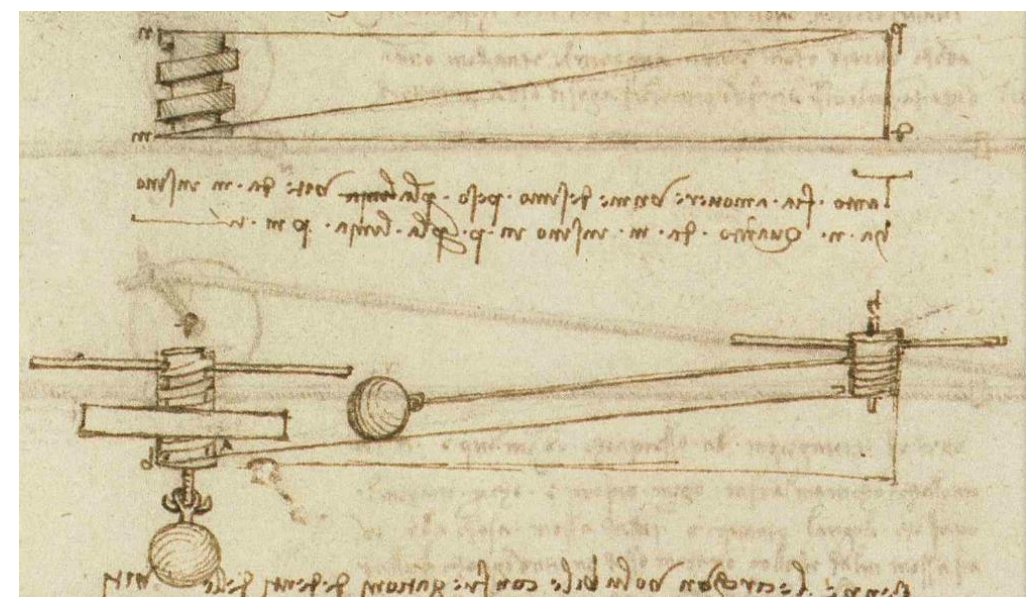

Fig. 18 Sketches showing the analogy between the action of a screw thread and traction of a mass up an inclined plane (Madrid I 86v, c. 1493-7)

He first explained his concepts for quantitative analysis of the problem soon afterwards. Fig. 17(b) provides an example of one approach (Arundel 187r, c. 1500-05, see also MS L 26v, c. 1497-1502). In order to calculate the force needed to pull a weight of 12 pounds up the slope $m c$, he argues that as point $b$ bisects $a c$, the body will have only half its 'natural weight' (gravità natural); so in the absence of friction the force needed will be 6 pounds. The friction is one quarter of the natural weight (i.e. 3 pounds) but as the weight is being pulled at the 'third level of obliquity' (i.e. at $30^{\circ}$ to the vertical), only one third of the friction is required. Thus the force needed to pull the body will be $6+1=7$ pounds. A correct treatment shows that in the absence of friction the force needed parallel to the slope would in fact be $12 \cos 30^{\circ}$ or 10.4 pounds, and the addition of friction would increase the force to 11.9 pounds. Some ten years later, he revisited the problem (MS E 78r, 78v, c. 1513-4), but was unable to improve on his analysis. In the intervening period (1506-8) he made the sketches in Fig. 1(a) which are not accompanied by any relevant notes. On the verso of the same folio (CA 532v) he made simpler sketches of blocks on inclined planes and noted in purely 
qualitative terms the difference in behaviour between bodies pulled upwards and downwards on a slope, and of a body which descends of its own accord.

\section{Leonardo's experiments}

Leonardo's methods of investigation, as Kemp has noted [3], were 'an untidy mixture of deductive and inductive reasoning, habitual observation, hands-on intervention, 'thought experiments', 'drawn experiments', actual experimental testing and analogy'. So to what extent might his sketches and notes relating to friction represent real experiments that he actually performed, rather than illustrations of concepts or of thought experiments?

Truesdell [44], perhaps the most sceptical critic of Leonardo's methods, wrote that 'of the hundreds of things he plans to try, or tells us to try, he never once records having tried a single one; from the hundreds of 'experiments' he projects, he never once records a datum obtained by measurement', but even Truesdell admitted that the value of one quarter which Leonardo repeatedly stated as the coefficient of friction must have been derived from experimental observation. Another example of an observation which must surely have originated from an experimental measurement is contained in Codex Madrid I (which was not available to Truesdell). It is Leonardo's use of a balance to compare the weights of a piece of iron in air and submerged in water (Madrid I 181r, c. 1493-7), and is perhaps unique in providing data which can be verified independently, as well as telling us something about the precision of his measurements and his attitude to experimental accuracy. He notes that iron which weighs 11 pounds in air weighs only 9 pounds in water: it 'loses' $2 / 11$ of its weight. These figures suggest a specific gravity for the iron of $5.5^{15}$, which can be compared with a true value between about 7 (for cast iron) and 7.8 (for wrought iron). The implied precision of

\footnotetext{
${ }^{15}$ Not 9 as suggested by Keele [5].
} 
measurement is not great as Leonardo states his weights only to the nearest pound; this was clearly a rough experimental test and Leonardo seems to have been more concerned with establishing the principle of the 'lost' weight than with its accurate quantification.

Govi [15] was in no doubt that Leonardo had carried out experiments, writing that 'he measured the weight needed to move bodies supported on horizontal planes, pulling them by cords carried over very mobile pulleys, and also experimented to find the angle of inclination needed for a plane so that bodies supported by it started to slip'. Black [16] repeated these statements, embellishing the description of the pulleys as 'well-adjusted'. Marcolongo [26] identified the sketches shown in Fig. 1(c) as representing Leonardo's apparatus, and his view was shared by Canestrini $[28,29]$ who constructed a single piece of apparatus based on both of these drawings for the major Leonardo exhibition in Milan in 1939. A later replica constructed in 1952 is now in the Museo Nazionale della Scienza e della Tecnologia in Milan $^{16}$. Both these confections employed an open-topped box for the body being pulled along the plane instead of the solid rectangular block shown in Leonardo's sketch, as well as hollow cylinders instead of the solid ones drawn by Leonardo. Reti [34] described the diagrams of Figs. 1(a) and (c) as 'friction banks ${ }^{17}$ devised by Leonardo (which) enabled him to measure the forces required to slide one surface across another when both are level or on an incline or when a rolling motion is involved' and compared them with the much later experimental apparatus of Coulomb. More recently, several authors have cited Dowson [1] and also interpreted the same diagrams as illustrating Leonardo's experiments [45-51].

However, as we have seen, Leonardo's first statement on sliding friction (Fig. 2: Forster III 72r) pre-dates the diagrams of Fig. 1 by some 7-12 years. His sketch in the Forster

\footnotetext{
${ }^{16}$ Banco per esperienze sull'attrito, inventory no. 392

${ }^{17}$ Both Marcolongo and Canestrini used the word 'banco' which is better translated here as 'apparatus' rather than as 'bank' or 'bench' in the sense of a workbench or laboratory bench.
} 
notebook appears to show a string passing over a pulley, rather than the roller that is very clearly drawn in the left-hand sketch of Fig. 1(c). There is no similar sketch of a string attached to a block and passing over a roller elsewhere in the notebooks, and the diagram is not accompanied by any explanatory text. One can only speculate as to Leonardo's purpose in drawing the roller. By changing the position of the roller on the slope, the height of the string above the horizontal plane could be easily adjusted, perhaps to allow blocks with different heights to be accommodated. Possibly he intended to avoid the effect of friction from a pulley, which would otherwise add to the friction force he was trying to measure. The use of a roller on a horizontal plane might certainly have that advantage, but a roller on a sloping plane as shown in the sketch would add a contribution to the tension in the string from its own weight, which would surely confuse the interpretation of the results.

The notebooks contain several sketches of blocks being pulled over planes by strings (e.g. Figs. 1(a) and (b), 4 and 5), and in some cases by strings passing over pulleys and attached to weights, as in Figs. 2, 3, 6 and 7. Figs. 9, 10(b) and 16 also show strings passing over pulleys and attached to weights and these are common elsewhere in Leonardo's drawings in other contexts; in many cases they are intended merely to indicate the direction and magnitude of a force and almost certainly do not represent experimental arrangements. Examples include illustrations of the forces on stones forming an arch (Madrid I 142v) and the variation of pressure with depth in a tank of water (Codex Leicester 6r). Fig. 4 shows an example of a 'force' exerted by a string represented simply by a line with a number beside it, and Fig. 8 provides examples of both methods of representation: a line with a number, and hanging weights.

While Leonardo tackled the problem of the weighted rotor in a half-bearing, represented by the right-hand sketch in Fig. 1(c) and the images in Fig. 13, repeatedly over many years, the methods he used for its analysis were convoluted and inconsistent, although they did 
sometimes yield approximate values for the coefficient of friction. However, he devised these methods of analysis some years after he had arrived at a value for the coefficient of friction ${ }^{18}$; he cannot have used this geometry as his primary empirical method for investigating friction. And as we have seen, Leonardo's quantitative understanding of friction on an inclined plane was insufficient for him to have deduced a value for the coefficient of friction from tests with that geometry; a correct treatment was first presented much later by Parent (1704), who also analysed the action of screws.

Although we cannot conclude that the diagrams showing a block being pulled along a horizontal plane by a string passing over a pulley and loaded by a weight are intended to represent real experiments rather than concepts, it is very hard to imagine any other experiment from which Leonardo could have drawn his conclusions about friction. He must somehow have varied the contact area and the weight independently, and been able to estimate the ratio between the friction force and the weight. His method very probably did involve using a variable weight on a string passing over a pulley, dragging a block or a stack of blocks on a horizontal plane as shown schematically in Figs. 2, 3 and 7. He sketched rather similar arrangements to these in 1493-5 in the context of measuring the effects of bending beams (CA 66r c. 1493-5, Windsor 12346r c. 1492-4), and at the same period also suggested a method of varying the load on the end of a piece of wire in order to measure its tensile strength, by pouring fine stones into a basket (CA 222r, c. 1493-4).

Although Leonardo repeatedly stated that the friction between bodies was 'one quarter of the weight', and in one case (CA 532v) stated explicitly that this derived from 'experience', he often qualified this with statements that the surfaces should be smooth, hard or dense. He also occasionally specified other ratios, one third or one half, and these are also the ratios

\footnotetext{
${ }^{18}$ see discussion of the sketch in Fig. 13a
} 
implicit in the pyramidal diagrams of Fig. 2. But the ratio of one quarter is notable not only because it is most frequently mentioned in his statements, but also because it is so consistently used, without explicit mention, in Leonardo's calculations. Amontons in 1699 [52] concluded from his experiments with iron, copper, lead and wood that the coefficient of sliding friction between all of these materials was the same, and equal to 'about one third'. But Amontons stated clearly that his samples were lubricated with pork lard ('vieux oingt'), and we must therefore question whether Leonardo's experiments were also performed under lubricated conditions.

There are three reasons why this suggestion is plausible: the context of his studies, the value of coefficient he chooses, and his observations on the effect of roughness. His earliest studies of friction on a plane coincided with his investigations of friction in axle bearings, and for both cases he adopts the same coefficient of friction. The axles of carriages and wagons were either wood or iron, fitted into holes in the wheels to form plain bearings, and these bearings would undoubtedly have been greased to assist their motion and reduce wear. Animal fats and soaps are explicitly mentioned as lubricants for axles and machinery used in the construction of Florence cathedral in the latter half of the fifteenth century [39], and their use dates back to much earlier times [1]: the Latin word 'axungia', a soft animal fat also used for medicinal purposes, was derived from the words for 'axle' and 'grease' [53].

Although Leonardo provides almost no information about the materials that he investigated, indirect inferences from his notebooks suggest that he used wood in his sliding experiments; the estimate of the density of the block shown in Fig. 5 supports this view, and the ease of obtaining and shaping wood into rectangular blocks, slabs and cylinders would suggest that he was unlikely to have used any other material for most of his tests. The coefficient of friction for wood sliding against wood or a metal surface varies according to the nature of the materials, the cleanliness and preparation methods of the surfaces, the applied 
pressure, sliding speed, and so on. But we can derive some typical values from historical and more modern sources. Desaguliers (1745) [54] tabulated data which yield coefficients of friction for unlubricated sliding of wood on wood between 0.35 and 0.5 . Coulomb (1785) [55] measured coefficients of static friction from 0.43 to 0.67 for various samples of unlubricated wood (oak, elm or pine) sliding against wood, and found that lubrication with tallow reduced the values to $0.1-0.2$, but with considerable dependence on the time for which the system had been under static load. Bowden and Tabor [32] reported a value of 0.6 for dry wood (Balsam fir) sliding on steel, while Rabinowicz [56] provided data ranging from 0.45 to 0.5 for wood (unspecified) sliding on steel. Blau [57] listed coefficients of static friction for wood on wood from eight separate sources; these were 0.25-0.5 (twice), 0.3-0.7, 0.6 (twice), 0.4, 0.54-0.62 and 0.43-0.62. Sathre and Gorman [58] found values close to 0.4 for the static friction of maple wood bearings on steel shafts, while lubrication with pork tallow reduced the values to between 0.18 and 0.24 . In a recent attempt to recreate Leonardo's friction experiments, Pitenis et al. [51] measured friction for various hardwood blocks sliding on a maple wood surface; for clean smooth wood samples they found coefficients of friction between 0.7 and 0.4 , while for samples with rough surfaces that had been deliberately contaminated ('sullied') with finger grease they measured values as low as 0.25 . Typical coefficients for unlubricated sliding of wood are thus significantly higher than Leonardo's value of one quarter, which is much more consistent with the values reported for lubricated sliding in the presence of a thin film of animal fat, and close to the value of about one third reported for lubricated sliding by Amontons.

The third piece of evidence which suggests that Leonardo's experiments were performed under lubricated conditions comes from his statements about the effect of roughness on friction, which repeatedly suggest that low friction is associated with smooth surfaces, and high with rough. This behaviour would be consistent with sliding under 
conditions of boundary lubrication, whereas the opposite effect (a decrease in friction with increasing roughness) would be expected for unlubricated surfaces [59].

\section{Discussion and conclusions}

While accepting that the dates assigned to Leonardo's manuscripts can only be approximate, we can now trace a clear path of development in his studies of friction. They were stimulated by practical applications, and appear to have originated before 1490 in his observations of the behaviour of the wheels and axles of carriages and wagons. By 1493 he was also showing an interest in other situations in which frictional forces were important, such as arch abutments and even the 'wedging' action by which a chimney-sweep held himself inside a vertical shaft (see footnote 5). He realised that the resistance to rotation of a wheel arose from friction at the axle bearing ${ }^{19}$, and his first statement of the laws of sliding friction in 1493/4 (Fig. 2) was followed almost immediately by attempts to apply them to axle friction in a cart (Fig. 11), and also to rotation of an isolated shaft (a rotor) in a much more abstract configuration (Fig. 13a). He continued to consider these and related problems, including more complex versions of the weighted rotor (e.g. Fig. 14) for at least the next ten years. His first notes on rolling friction are of a similar date to those on sliding, although he did not attempt a quantitative treatment. Leonardo's interest in friction on an inclined plane originated from considerations of the action of screw threads (Fig. 17) and lasted from about 1493 until at least 1515, but despite his persistence this geometry was beyond his powers of quantitative analysis.

\footnotetext{
${ }^{19}$ Quite separately, Leonardo also commented on how the size of the wheel affected the ease of traction, due to the rolling resistance that originated at the wheel-ground interface (CA 561r, Forster II 124r, MS L 72r)
} 
The major development in Leonardo's understanding of friction occurred from about 1493 to 1500 , while he was employed by the duke of Milan, Ludovico Sforza, as military engineer, architect, sculptor and painter [3]. By the end of that period he was confident about the laws of friction, although the value he chose for the coefficient of friction varied considerably. Values of $1 / 2,1 / 3,1 / 4$ and even $1 / 8$ are recorded in his notebooks and he fully appreciated that the value depended on the nature of the surfaces and the state of lubrication. From the time he left Milan for Florence in 1500 and for the next 15 years, however, he almost exclusively used a value of $1 / 4$ in the many calculations he subsequently recorded. This value is much more consistent with lubricated conditions than with unlubricated sliding. The reason for his use of $1 / 4$ surely cannot be that he believed that this always represented the true value, as has been assumed by many commentators from Govi onwards. It seems much more plausible, as Canestrini has also suggested [28] that Leonardo used the value of $1 / 4$ because it was a convenient number for his calculations. As noted earlier, his thought experiments usually postulated dimensions and weights that with his rather poor grasp of arithmetic he found easy to manipulate. The assumption, for example, that a body had a weight of four pounds and that the coefficient of friction was one quarter made calculation very straightforward. Leonardo's multiple analyses of the mechanics of balances, pulleys and axles often amount to repeated working of similar problems with a different set of conditions. He takes the friction ratio to be $1 / 4$, even after he has made it clear that he knows that it may well have a different value, largely for convenience in his calculation; he uses 'one quarter' as a placeholder, in the absence of an algebraic symbol, for the true ratio ${ }^{20}$. In considering friction on an inclined plane, for example, he writes 'if the friction of every weight is equal to a quarter of that weight ......' and then continues with his calculation (MS L 26v, c.1497-

\footnotetext{
${ }^{20}$ Leonardo did not use algebra [3]. His calculations always involve numbers, sometimes being extended to a more general case by use of the Rule of Three.
} 
1502). But if the friction were different, he is telling the reader, you can readily see how you should carry out the calculation.

We can now see the diagrams of Fig. 1 in their proper context. They date from 1500-5 (Fig. 1b) and 1506-8 (Fig. 1a and b), well after Leonardo had established a firm understanding of friction. The sketches of Fig. 1(a) and (b) are found on a page (CA 532r) which is otherwise blank apart from a heading; there is no reference to the letters which label the blocks, and the page is evidently unfinished. There is no reason to suppose that they represent actual experiments rather than schematic diagrams to illustrate statements in the accompanying text that would have been added later. Leonardo was never capable of correctly analysing the problem of friction on an inclined plane. The points of attachment for the 'strings' in Fig. 1(b) are not consistent with this representing an actual experiment, since for a coefficient of friction greater than about 0.2 the second block (labelled $b$ ) would topple rather than slide; this is in contrast to the arrangement sketched in Fig. 5 at a similar date which provides a more plausible experimental set-up. However, the diagram of Fig. 1(b) does remain helpful as indicating the kinds of experiments that Leonardo may well have performed to investigate the effect of contact area on friction. The drawings of Fig. 1(c) are considerably more misleading. The left-hand sketch, with its unusual roller on a slope, must surely represent a thought-experiment, and if the right-hand sketch does indeed show an experimental apparatus, then it is much more likely to have been used to investigate the mechanics of a loaded rotor than the fundamentals of friction. Dating from the publications of Marcolongo and Canestrini in the 1930s [26-29] and Canestrini's construction of models based on these drawings, followed by Reti [34] and subsequent authors, these drawings have received undue prominence and give a false impression of Leonardo's methods.

While it may not be possible to identify unequivocally the empirical methods by which Leonardo arrived at his understanding of friction, his achievements more than 500 years ago 
were outstanding. He made tests, he observed, and he made powerful connections in his thinking on this subject as in so many others. By1493 he had elucidated the fundamental laws of friction which would be re-discovered by Amontons some 200 years later, and he then developed and applied them with varying degrees of success to practical mechanical systems. His use and understanding of the ratio between frictional force and weight was much more nuanced than many have suggested; he had a good appreciation of the factors that affected it, and while he may have used a single value for the coefficient of friction on many occasions, it was very probably for convenience of calculation. Leonardo's interest in friction was deeprooted; not only did he seek the answers to practical problems such as the force needed to pull a wagon, turn an axle or pull a weight up a slope, but he also strove with some success to model these processes with the limited mathematical tools at his disposal. Paradoxically, even though his work remained unknown to tribologists until well into the twentieth century and thus had no influence on the development of the subject, Leonardo da Vinci stands in a unique position as a quite remarkable and inspirational pioneer of tribology.

\section{References}

[1] D. Dowson, History of tribology, Longman, London, 1979.

[2] L. Reti, The Leonardo da Vinci codices in the Biblioteca Nacional of Madrid, Technology and Culture, 8(4) (1967) 437-445.

[3] M. Kemp, Leonardo da Vinci, Experience, experiment and design, V \& A Publications, London, 2006.

[4] K.H. Veltman, Leonardo da Vinci: a review, Leonardo 41(4) (2008) 381-388

[5] K.D. Keele, Leonardo da Vinci's elements of the science of man, Academic Press, London, 1983. 
[6] C. Pedretti, The literary works of Leonardo da Vinci compiled and edited from the original manuscripts by Jean Paul Richter; commentary by Carlo Pedretti, University of California Press, Berkeley, 1977.

[7] J.P. Richter, The literary works of Leonardo da Vinci, Sampson Low, Marston, Searle and Rivington, London, 1883.

[8] C. Pedretti, The Codex Atlanticus of Leonardo da Vinci: a catalogue of its newly restored sheets, Johnson Reprint Co., New York, 1979.

[9] C. Pedretti, Saggio di una cronologia dei fogli del Codice Arundel di Leonardo da Vinci, Bibliothèque d'Humanisme et Renaissance 22(1) (1960) 172-177.

[10] C. Pedretti (ed.), Leonardo da Vinci: fragments at Windsor Castle from the Codex Atlanticus, Phaidon Press, London,1957.

[11] A. Marinoni, I codici Forster del Victoria and Albert Museum di Londra: edizione in facsimile sotto gli auspice della Commissione nazionale vinciana; trascrizione diplomatica e critica, Giunti Barbèra, Firenze, 1992.

[12] L. Reti, The Madrid codices, McGraw-Hill, New York, 1974.

[13] J.-B. Venturi, Essai sur les ouvrages physico-mathématiques de Léonard de Vinci, Duprat, Paris 1797.

[14] G. Libri, Histoire des sciences mathématiques en Italie, Tome 3ème, Jules Renouard, Paris, 1840.

[15] G. Govi, Leonardo letterato e scienziato, in C. Belgiojoso (Ed.) Saggio delle opere di Leonardo da Vinci, Ricordi, Milano, 1872, pp. 5-22.

[16] C.C. Black, Leonardo da Vinci in science and literature, in C.W. Heaton, Leonardo da Vinci and his works, Macmillan, London,1874, pp.115-180.

[17] G. Séailles, Léonard de Vinci l'artiste et le savant, Didier, Paris, 1892.

[18] H. Grothe, Leonardo da Vinci als Ingenieur und Philosoph, Nicolaische Verlagsbuchhandlung, Berlin, 1874.

[19] T. Beck, Beiträge zur geschichte des Maschinenbaues, Springer, Berlin, 1900. 
[20] J.P. Richter, I.A. Richter, The literary works of Leonardo da Vinci, 2nd edn., London 1939.

[21] E. MacCurdy, The notebooks of Leonardo da Vinci, Jonathan Cape, London, 1938.

[22] P. Duhem, Les origines de la statique, Hermann, Paris, 1905.

[23] P. Duhem, Ètudes sur Léonard da Vinci: ceux qu'il a lus et ceux qui l'ont lu, Hermann, Paris, 3 vols., 1906-13.

[24] F. Schuster, Zur mechanik Leonardo da Vincis, dissertation, Friedrich-AlexandersUniversität, Erlangen, 1915.

[25] I.B. Hart, The mechanical investigations of Leonardo da Vinci, Chapman and Hall, London, 1925.

[26] R. Marcolongo, La meccanica di Leonardo da Vinci, Atti della Reale Accademia delle Scienze Fisiche e Matematiche, ser. 2, 19(2) (1933) 1-110.

[27] R. Marcolongo, La meccanica vinciana, in Leonardo da Vinci, edizione curata dalla Mostra di Leonardo da Vinci in Milano, Istituto geographico De Agostini, Novara, 1939, pp. 483-492.

[28] G. Canestrini, Le macchine di Leonardo, in Leonardo da Vinci, edizione curata dalla Mostra di Leonardo da Vinci in Milano, Istituto geographico De Agostini, Novara, 1939, pp. 493-507.

[29] G. Canestrini, Leonardo: costruttore di macchine e di veicoli, Tumminelli, Milano, 1939.

[30] A. Uccelli, I libri di meccanica nella ricostruzione ordinate di Arturo Uccelli, Hoepli, Milano, 1940.

[31] F.P. Bowden, D. Tabor, The friction and lubrication of solids, Clarendon Press, Oxford, 1950.

[32] F.P. Bowden, D. Tabor, The friction and lubrication of solids, Part II, Clarendon Press, Oxford, 1964.

[33] F.P. Bowden, D. Tabor, Friction: an introduction to tribology, Heinemann, London, 1974.

[34] L. Reti, Leonardo on bearings and gears, Sci. Am. 224(2) (1967) 101-110. 
[35] D. Dowson, Men of tribology: Leonardo da Vinci, Trans. ASME: J. Eng. Tribology 99(4) (1977) 382-386.

[36] E. McCurdy, The mind of Leonardo da Vinci, Jonathan Cape, London 1928

[37] E. Maclagan, An apocryphal saying of Leonardo da Vinci, Times Lit. Supp., 8 March 1923, Issue 1103, p. 159.

[38] M. Kemp, Leonardo da Vinci, The marvellous works of nature and man, J.M. Dent, London, 1981.

[39] J. Muendel, Friction and lubrication in medieval Europe: the emergence of olive oil as a superior agent, Isis, 86(3) (1995) 373-393

[40] C. Nicholl, Leonardo da Vinci, Allen Lane, London, 2004.

[41] R.E. Zupko, Italian weights and measures from the Middle Ages to the nineteenth century, American Philosophical Society, Philadelphia, 1981.

[42] H.E. Desch, Timber, $6^{\text {th }}$ edn., Macmillan, London, 1981.

[43] D.E. Smith, History of mathematics, vol. 2, Ginn, Boston, 1925.

[44] C. Truesdell, The mechanics of Leonardo da Vinci, in C. Truesdell, Essays in the history of mechanics, Springer, Berlin, 1968.

[45] J.A. Williams, Engineering tribology, Oxford University Press, Oxford, 1994.

[46] B.N.J. Persson, Sliding friction, Springer, Berlin, 1998.

[47] E. Meyer, T. Gyalog, R.M. Overney, K. Dransfeld, Nanoscience: friction and rheology on the nanometer scale, World Scientific Press, Singapore, 1998.

[48] J. Krim, Surface science and the atomic-scale origins of friction: what once is old is new again, Surface Sci. 500 (2002) 741-758.

[49] M. Marder, Terms of detachment, Nature Materials 3 (2004) 583-4.

[50] U. Besson, Historical scientific models and theories as resources for teaching and learning: the case of friction, Sci. and Educ.22 (2013) 1001-1042

[51] A.A. Pitenis, D. Dowson, W.G. Sawyer, Leonardo da Vinci's friction experiments: an old story acknowledged and repeated, Tribol. Lett. 56 (2014) 509-515 
[52] G. Amontons, De la resistance causée dans les machines, Memoires de l'Academie Royale, Paris, 1699, pp.206-222

[53] H.A. Harris, Lubrication in antiquity, Greece and Rome 21(1) (1974) 32-36

[54] J. Desaguliers, A course of experimental philosophy, vol. 1, London, 1745

[55] C.A. Coulomb, Théorie des machines simples, Collection des Mémoires de l'Académie des Sciences de Paris, 10 (1785) 163-332.

[56] E. Rabinowicz, Friction and wear of materials, $2^{\text {nd }}$. edn., John Wiley, New York, 1995

[57] P.J. Blau, The significance and use of the friction coefficient, Trib. Int. 34 (2001) 585591.

[58] R. Sathre, T. Gorman, Improving the performance of wooden journal bearings, Forest Products J. 55(11) (2005) 41-47.

[59] I. Etsion, Comment on Leonardo da Vinci's friction experiments: an old story acknowledged and repeated, Tribol. Lett. 58 (2015) 33. 